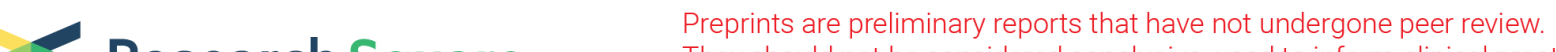 Research Square They should not be considered conclusive, used to inform clinical practice, or referenced by the media as validated information.
}

\section{Factors Associated With Bone Health Status of Malaysian Pre-adolescent Children in the PREBONE- kids Study}

\section{Chung Yuan Chang}

International Medical University https://orcid.org/0000-0003-1851-9110

\section{Kanimolli Arasu}

International Medical University

Soon Yee Wong

International Medical University

\section{Shu Hwa Ong}

International Medical University

Wai Yew Yang

International Medical University

Megan Hueh Zan Chong

International Medical University

Meenal Mavinkurve

International Medical University

Erwin Jiayuan Khoo

International Medical University

Karuthan Chinna

Taylor University

Connie M. Weaver

Purdue University

Winnie Siew Swee Chee ( $\nabla$ Winnie_Chee@imu.edu.my )

1Department of Nutrition \& Dietetics, School of Health Sciences, International Medical University, 57000 Bukit Jalil, Kuala Lumpur, Malaysia https://orcid.org/0000-0003-3424-3943

\section{Research article}

Keywords: bone mineral density, body composition, vitamin D, calcium, prepubertal, Malaysia

Posted Date: September 17th, 2020

DOl: https://doi.org/10.21203/rs.3.rs-77049/v1 
License: (c) (i) This work is licensed under a Creative Commons Attribution 4.0 International License. Read Full License

Version of Record: A version of this preprint was published at BMC Pediatrics on September 3rd, 2021. See the published version at https://doi.org/10.1186/s12887-021-02842-6. 


\section{Abstract}

Background: Modifiable lifestyle factors and body composition can affect the attainment of peak bone mass during childhood. This study performed a cross-sectional analysis of the determinants of bone health among pre-adolescent Malaysian children with habitually low calcium intakes and vitamin D status in Kuala Lumpur (PREBONE-Kids Study).

Methods: Body composition, bone mineral density (BMD), and bone mineral content (BMC) at the lumbar spine (LS) and total body (TB) were assessed using dual-energy X-ray absorptiometry (DXA). Calcium intake was assessed using 1-week diet history, MET (metabolic equivalent of task) score using CPAQ questionnaire, and serum 25(OH) vitamin D using LC-MS/MS.

Results: The mean calcium intake was $348.8 \pm 180.1 \mathrm{mg} /$ day and mean serum $25-\mathrm{OH}$ vitamin $\mathrm{D}$ level was $43.9 \pm 14.5 \mathrm{nmol} / \mathrm{L}$. In boys, lean mass (LM) was significantly associated with LSBMC $(\beta=0.539$, $p<0.001)$, LSBMD $(\beta=0.607, p<0.001), \operatorname{TBBMC}(\beta=0.675, p<0.001)$ and TBBMD $(\beta=0.481, p<0.01)$. Height was significantly associated with LSBMC $(\beta=0.346, p<0.001)$ and TBBMC $(\beta=0.282, p<0.001)$ while fat mass (FM) $(\beta=0.261, p=0.034)$ and MET score $(\beta=0.163, p=0.026)$ were significant predictors of TBBMD. Among girls, LM was significantly associated with LSBMC $(\beta=0.620, p<0.001)$, LSBMD $(\beta=0.700, p<0.001)$, TBBMC $(\beta=0.542, p<0.001)$ and TBBMD $(\beta=0.747, p<0.001)$. Calcium intake was a significant predictor of LSBMC $(\beta=0.102, p=0.034)$, TBBMC $(\beta=0.122, p<0.001)$ and TBBMD $(\beta=0.196$, $p=0.002)$ in girls. Lean mass (LM) was weakly correlated with MET scores $(r=0.205, p=0.001)$ but not protein $(r=0.055, p=0.393)$ or energy intake $(r=0.101, p=0.117)$. MET score $(\beta=0.207, p=0.043)$ was a significant predictor of LM in boys but no factor was found to predict LM in girls.

Conclusion: $\mathrm{LM}$ is the major determinant of $\mathrm{BMC}$ and $\mathrm{BMD}$ among pre-adolescent Malaysian children and physical activity is a significant predictor of LM in boys. Encouraging physical activity, calcium intake and optimum diets that build lean body mass should be the focus for developing public health guidance to ensure optimal bone health status during rapid growth.

\section{Background}

Prepubertal age is an important period in life for rapid growth and bone accretion leading to peak bone mass attainment during adolescence and early adulthood. Accumulation of bone mass during this rapid growth phase is important for the prevention of osteoporosis at adulthood (1). A 10\% increase in peak bone mass is estimated to halve the risk of an osteoporotic fracture in adult life (2).

Genetics may determine approximately $80 \%$ of bone mineral density (BMD) acquisition during childhood, however, modifiable factors including nutrition, physical activity and body composition are estimated to affect up to $20 \%$ of BMD $(3,4)$. A National Osteoporosis position paper which included a systematic review of all lifestyle factors influencing development of peak bone mass concluded that evidence was sufficient to achieve an A grade (strongest evidence with consistent findings from multiple representative studies) for only calcium intake and physical activity (5). Calcium is the major constituent of bone 
mineral and increasing dietary calcium towards recommended intakes suppresses bone resorption. Physical activity and exercise exert a continuous stimulus on bone as a living tissue that responds to mechanical load, and therefore, is essential to maintain a normal bone mass (6). An adequate level of Vitamin D status received a B grade level of evidence (5). Adequate vitamin D status facilitates calcium absorption by the vitamin D-dependant pathway, more dominant when calcium intake is low, necessary for normal calcification of the growth plate and the mineralization of bones.

Body weight, a genetically determined factor that is also modifiable, is one of the strongest predictors of bone mass $(5,8)$. Between the two main components of body weight, lean mass (LM) and fat mass (FM), it remains uncertain which one exerts a greater effect on bone mass accretion during puberty. In a recent systematic review by Sioen and colleagues (7), LM consistently showed a significant positive association with $\mathrm{BMD}$ and bone mineral content (BMC). The role of body fat on bone acquisition is contradictory and may depend on the nature of the fat (amount and distribution) as well as sex and pubertal status.

While the burden of osteoporotic fractures is markedly increasing around the world, the greatest impact is expected to occur in Asia with Malaysia being projected to have the highest increase of up to 3.55 -fold in hip fractures by the year 2050 due to a rapidly ageing population (8). Osteoporosis is often called a childhood disease because building peak bone mass occurs in childhood. Although it is widely reported that Asian children have habitually low calcium intakes and a high prevalence of vitamin D deficiency ( 9 , 10), a recent systematic review revealed that there are limited Asian studies examining the association of these conditions with BMD attainment (5). Malaysian prepubertal children have been reported to have calcium intakes below $500 \mathrm{mg} /$ day, low physical activity levels and low serum vitamin D status (10-13). In addition, Malaysia has the second-highest rate of childhood obesity in South East Asia with a prevalence of $16.5 \%$ in children aged 8-12 years old (14). Therefore, a better understanding of the role of body composition on skeletal health and factors associated with low LM and high FM become important. This study performed a cross-sectional analysis on the determinants of bone health among preadolescent Malaysian children with habitual low calcium intakes and low vitamin D status from the baseline data of the PREBONE-Kids Study. We hypothesized that dietary intake, physical activity and vitamin D status had an impact on BMC and BMD among pre-adolescent Malaysian children.

\section{Methods}

\subsection{Study design and participants}

A cross-sectional analysis was performed on the baseline data from the participants of a 1 year randomized, double-blind, placebo-controlled trial of soluble corn fiber (SCF) on bone indices (PREBONEKids Study) in Kuala Lumpur (ClinicalTrials.gov identifier: NCT03864172). Baseline data were collected from 243 school children aged 8 to 11 years (127 boys and 116 girls) recruited for the 1-year study during the period of March 2017 through March 2018. Ethical approval for the study was obtained from the Research and Ethics Committee of the International Medical University (IMU) (Trial no: R182/2016). 
Informed consent was obtained from parents or legal guardians and assents were obtained from the participants.

The study included participants who were healthy as determined by a standard medical assessment, Tanner Stage 1 or 2 based on breast development for girls and pubic hair in boys, premenarcheal for girls and able to provide assent. Participants were excluded if they had a history of serious medical conditions and received therapy with medications known to interfere with bone metabolism (e.g. steroids, hormones, diuretics, cortisone or anti-seizure medication).

\subsection{Measurements}

Anthropometry measurements were taken by trained research assistants following the International Society for the Advancement of Kinanthropometry (ISAK) standard procedures (15). The height was measured using vertical stadiometer (SECA 206, Hamburg, Germany) to the nearest 0.1 centimetres $(\mathrm{cm})$ and weight was measured using a portable digital scale (Tanita HD-301, Tanita Corporation, Japan) to the nearest 0.1 kilograms $(\mathrm{kg})$. BMl values were computed as the ratio between weight $(\mathrm{kg})$ and the square of height (meter). In this study standardized BMI values based on World Health Organization were used to classify the participants into four BMI categories; thin (BMI Z-score $<-2.0$ ), normal $(\geq-2.0, \leq 1.0)$, overweight (BMI Z-score >1.0, $\leq 2.0$ ) and obese (BMI Z-score >2.0) (16).

Total body and lumbar spine bone density and total body composition were measured using GE Lunar iDXA (GE Healthcare, USA) with paediatric software (Lunar enCORE version 13.60.033) using population references for Asian children (17). The dual-energy X-ray absorptiometry (DXA) scans provided measurements of BMC and BMD for the total body (TBBMC and TBBMD) and lumbar spine L1-L4 (LSBMC and LSBMD) as well as lean mass (LM), fat mass (FM) and percent body fat (BF\%). The coefficient of variation (CV\%) of the phantom was $0.35 \%$. Imaging technician's CV\% for TBBMD, SPBMD, LM and FM were $0.42 \%, 0.83 \%, 1.37 \%$ and $0.86 \%$ respectively.

The participants were interviewed on their 7-days diet history by a research assistant and their intakes were verified with their parents or guardian. Calcium intake was analysed using Nutritionist Pro Diet Analysis Software (version 7.4.0, 2019, Axxya Systems, LLC, USA) in which Nutrient Composition of Malaysian Foods (Tee et al., 1997) was the primary data source. Alternatively, for foods that were not available in the Malaysian food database, the Singapore Energy and Nutrient Composition of Food was used. In addition, nutrient labels were used for the calcium content of manufactured food products and beverages.

Physical activity level (PA) was measured using a physical activity questionnaire (cPAQ Malay version) which has been validated among Malaysian children (18). The questionnaire consisted of 3 sections: habitual activities (transportation, school activities, extra-curriculum, sport and club activities), leisure activities and housework. Metabolic equivalent task (MET) score was calculated based on Ainsworth et al. $(18,19)$. and Kemper et al. (20). 
Non-fasting blood samples were collected for serum $25-\mathrm{OH}$ vitamin D analysis. Serum samples were extracted through centrifugation at $1500-2000 \mathrm{~g}$ for 10 mins at $4^{\circ} \mathrm{C}$. The serum samples were then stored at $-80^{\circ} \mathrm{C}$ in an upright position until analysis for $25(\mathrm{OH}) \mathrm{D}$. All vitamin $\mathrm{D}$ metabolites were analysed by liquid chromatography-tandem mass spectrometry (LC-MS/MS) with an Agilent 1260 Infinity liquid chromatograph (Agilent Technologies, Waldbronn, Germany) coupled to a QTRAP ${ }^{\circledR} 5500$ tandem mass spectrometer (AB SCIEX, Foster City, CA, USA) using a MassChrom ${ }^{\circledR} 25-\mathrm{OH}$-Vitamin D3/D2 in serum/plasma reagent kit including a 3-epi-25-OH-Vitamin D3/D2 upgrade diagnostics kit (Chromsystems, Munich, Germany). All analyte values of the calibrator and control were traceable to certified substances and standard reference materials of the National Institute of Standards and Technology. The coefficients of variation of serum 25(OH)D3, 25(OH)D2, and 3-epi-25(OH)D3 were 5.9\%, $3.3 \%$ and $4.6 \%$ respectively.

\subsection{Statistical analysis}

The distribution of variables were assessed based on skewness and kurtosis values (21). Quantitative variables were described as either medians and ranges or means \pm standard deviation (SD). Independent sample t-test was used to examine the mean differences in the quantitative variables between boys and girls. Qualitative variables were reported as frequencies and percentage. Associations between variables were tested using Pearson's correlation coefficients. Multiple linear regression analysis was used to determine significant predictors of BMD and BMC at the lumbar spine and total body. Multicollinearity was tested and in the final model, only variables that were significant in the stepwise analysis were considered. All calculations were performed using Statistical Package for the Social Sciences (SPSS) version 21.0 for Windows. In all tests, a $p$-value of less than 0.05 was considered to be statistically significant.

\section{Results}

The descriptive characteristics of the participants are shown in Table 1. The participants were predominantly Malays (90.5\%) followed by Indians (9.5\%). The mean age was $10.1 \pm 1.0$ years. The majority of the participants were in Tanner Stage 1 (95\%) while a small percentage were in Tanner Stage $2(5 \%)$.

There were no significant differences between males and females in the mean weight, height and BMI. Among the participants, $15.2 \%$ were overweight and $17.7 \%$ were obese. Among the boys, $9(7.0 \%)$ were thin, 76 (59.4\%) were normal weight, 16 (12.5\%) overweight and 27 (21.1\%) obese whereas among the girls, 12 (10.4\%) were thin, 66 (57.4\%) were normal weight, 21 (18.3\%) overweight and 16 (13.9\%) obese. Although boys and girls had similar fat mass, the proportion of fat to body weight as measured by BF\% was higher among the girls $(31.06 \pm 7.39 \%)$ compared to the boys $(28.82 \pm 9.17 \%, p=0.035)$. The LM was higher among the boys $(22.50 \pm 5.40 \mathrm{~kg})$ compared to the girls $(21.00 \pm 5.07 \mathrm{~kg}, p=0.026)$. The TBBMC (boys: $1160.4 \pm 237.9 \mathrm{~g}$ vs girls: $1095.6 \pm 220.6 \mathrm{~g}, p=0.029$ ) and TBBMD (boys: $0.780 \pm 0.075$ 
$\mathrm{g} / \mathrm{cm}^{2}$ vs girls: $0.754 \pm 0.072 \mathrm{~g} / \mathrm{cm}^{2}, p=0.006$ ) were significantly higher in boys compared to girls. There were no significant sex differences in LSBMC, LSBMD, bone area or BMD Z-scores.

Table 1: Descriptive characteristics of participants $(\mathrm{N}=243)$ 


\begin{tabular}{|c|c|c|c|c|}
\hline & Total $(n=243)$ & Boys $(n=127)$ & Girls $(n=116)$ & $p$-value \\
\hline Age & $10.1 \pm 1.0$ & $10.2 \pm 0.9$ & $10.0 \pm 1.0$ & 0.122 \\
\hline \multicolumn{5}{|l|}{ Ethnicity } \\
\hline Malay & $220(90.5)$ & $110(86.6)$ & $110(94.8)$ & \\
\hline Indian & $23(9.5)$ & $17(13.4)$ & $6(5.2)$ & \\
\hline \multicolumn{5}{|l|}{ Tanner stage } \\
\hline Stage 1 & $230(94.7)$ & $125(98.4)$ & $105(90.5)$ & \\
\hline Stage 2 & $13(5.3)$ & $2(1.6)$ & $11(9.5)$ & \\
\hline Weight (kg) & $34.0 \pm 12.1$ & $34.7 \pm 13.3$ & $33.1 \pm 10.8$ & 0.292 \\
\hline Height (cm) & $135.8 \pm 9.1$ & $136.1 \pm 8.9$ & $135.4 \pm 9.5$ & 0.580 \\
\hline $\mathrm{BMI}\left(\mathrm{kg} / \mathrm{m}^{2}\right)$ & $18.0 \pm 4.5$ & $18.3 \pm 4.8$ & $17.7 \pm 4.2$ & 0.332 \\
\hline BMI-for-age Z-score & $0.187 \pm 1.693$ & $0.321 \pm 1.742$ & $0.040 \pm 1.632$ & 0.198 \\
\hline \multicolumn{5}{|c|}{$\begin{array}{l}\text { BMI Z-score classification, } \mathrm{n} \\
(\%)\end{array}$} \\
\hline Thinness & $21(8.7)$ & $9(7.1)$ & $12(10.3)$ & \\
\hline Normal & $142(58.4)$ & $74(58.3)$ & $67(57.8)$ & \\
\hline Overweight & $37(15.2)$ & $18(14.2)$ & $21(18.1)$ & \\
\hline $\begin{array}{l}\text { Overweight } \\
\text { Obese }\end{array}$ & $43(17.7)$ & $26(20.5)$ & $16(13.8)$ & \\
\hline \multicolumn{5}{|l|}{ Bone parameters } \\
\hline \multicolumn{5}{|l|}{ Lumbar Spine (LS) } \\
\hline Area $\left(\mathrm{cm}^{2}\right)$ & $29.7 \pm 4.2$ & $30.0 \pm 4.1$ & $29.3 \pm 4.3$ & 0.182 \\
\hline $\mathrm{BMC}(\mathrm{g})$ & $21.7 \pm 5.2$ & $21.6 \pm 4.7$ & $21.9 \pm 5.7$ & 0.725 \\
\hline $\operatorname{BMD}\left(\mathrm{g} / \mathrm{cm}^{2}\right)$ & $0.725 \pm 0.091$ & $0.715 \pm 0.081$ & $0.736 \pm 0.100$ & 0.064 \\
\hline \multicolumn{5}{|l|}{ Total Body (TB) } \\
\hline Area $\left(\mathrm{cm}^{2}\right)$ & $1462.0 \pm 184.6$ & $1480.5 \pm 188.3$ & $1441.8 \pm 179.0$ & 0.102 \\
\hline $\mathrm{BMC}(\mathrm{g})$ & $1129.5 \pm 231.6$ & $1160.4 \pm 237.9$ & $1095.6 \pm 220.6$ & $0.029 *$ \\
\hline $\mathrm{BMD}\left(\mathrm{g} / \mathrm{cm}^{2}\right)$ & $0.768 \pm 0.075$ & $0.780 \pm 0.075$ & $0.754 \pm 0.072$ & $0.006^{* *}$ \\
\hline BMD z-score & $0.789 \pm 0.960$ & $0.890 \pm 0.921$ & $0.678 \pm 0.994$ & 0.087 \\
\hline
\end{tabular}




\begin{tabular}{|c|c|c|c|c|}
\hline Area $\left(\mathrm{cm}^{2}\right)$ & $1234.5 \pm 183.7$ & $1251.0 \pm 187.8$ & $1216.5 \pm 178.2$ & 0.143 \\
\hline $\mathrm{BMC}(\mathrm{g})$ & $815.5 \pm 220.3$ & $836.6 \pm 231.3$ & $792.4 \pm 206.2$ & 0.118 \\
\hline $\operatorname{BMD}\left(\mathrm{g} / \mathrm{cm}^{2}\right)$ & $0.650 \pm 0.086$ & $0.658 \pm 0.088$ & $0.642 \pm 0.082$ & 0.140 \\
\hline \multicolumn{5}{|l|}{ Body composition } \\
\hline LM (kg) & $21.79 \pm 5.29$ & $22.50 \pm 5.40$ & $21.00 \pm 5.07$ & $0.026^{*}$ \\
\hline $\mathrm{FM}(\mathrm{kg})$ & $10.93 \pm 7.08$ & $11.00 \pm 7.98$ & $10.85 \pm 5.98$ & 0.876 \\
\hline $\mathrm{BF}(\%)$ & $29.87 \pm 8.44$ & $28.82 \pm 9.17$ & $31.06 \pm 7.39$ & $0.035^{\star}$ \\
\hline Serum 25(OH)D (nmol/L) & $43.9 \pm 14.5$ & $50.3 \pm 13.7$ & $36.8 \pm 11.9$ & $<0.001^{\star *}$ \\
\hline Energy (Kcal) & $\begin{array}{l}1457 \pm 450 \\
\text { (IQR: } 1129- \\
\text { 1711) }\end{array}$ & $\begin{array}{l}1543 \pm 463 \\
(\text { IQR: } 1213- \\
1778)\end{array}$ & $\begin{array}{l}1363 \pm 417 \\
\text { (IQR: } 1071- \\
1574)\end{array}$ & $0.002^{*}$ \\
\hline Protein intake & $\begin{array}{l}61.4 \pm 21.6 \\
\text { (IQR: } 48.2- \\
69.7)\end{array}$ & $\begin{array}{l}65.7 \pm 23.3 \\
\text { (IQR: } 50.8- \\
72.8)\end{array}$ & $\begin{array}{l}56.6 \pm 18.7 \\
\text { (IQR: } 44.0- \\
66.6)\end{array}$ & $0.001 *$ \\
\hline Calcium intake (mg) & $\begin{array}{l}349 \pm 180 \\
(\text { IQR: } 218-459)\end{array}$ & $\begin{array}{l}356 \pm 166 \\
(\text { IQR: } 217-468)\end{array}$ & $\begin{array}{l}341 \pm 194 \\
\text { (IQR: } 218-452)\end{array}$ & 0.510 \\
\hline Vitamin $D(\mu \mathrm{g})$ & $\begin{array}{l}1.5 \pm 1.6 \\
\text { (IQR: } 0.3-2.2)\end{array}$ & $\begin{array}{l}1.5 \pm 1.6 \\
\text { (IQR: } 0.4-2.3 \text { ) }\end{array}$ & $\begin{array}{l}1.4 \pm 1.6 \\
(\text { IQR: } 0.2-2.1)\end{array}$ & 0.638 \\
\hline PA level (MET scores) & $822 \pm 447$ & $961 \pm 502$ & $670 \pm 317$ & $<0.001^{* *}$ \\
\hline
\end{tabular}

Abbreviation: BMI, body mass index; LM, lean mass; FM, Fat mass; BF, body fat; 25(OH)D, 25 hydroxyvitamin D; PA, physical activity; IQR, interquartile range; MET, metabolic equivalent task.

${ }^{*}{ }^{*}$ indicates significantly different between $\operatorname{sex}\left({ }^{*} p<0.05,{ }^{* *} p<0.01\right)$.

The mean calcium intake for all participants was $349 \pm 180 \mathrm{mg} /$ day (range: $218-459 \mathrm{mg} /$ day) which met only about $25 \%$ of the recommended calcium intake for Malaysian children in this age-group. The calcium intakes were equally low in both boys and girls. Protein intake was significantly higher among boys than girls $(65.7 \pm 23.3 \mathrm{~g}$ vs $56.6 \pm 18.7 \mathrm{~g} ; p=0.001)$. In terms of physical activity MET scores, the boys were significantly more active than girls (boys: $961 \pm 502$ vs girls: $670 \pm 317, p<0.001$ ). The overall mean serum $25-\mathrm{OH}$ vitamin $\mathrm{D}$ level was $43.9 \pm 14.5 \mathrm{nmol} / \mathrm{L}$. The level was significantly higher among the boys (boys: $50.3 \pm 13.7 \mathrm{nmol} / \mathrm{l}$ vs girls: $36.8 \pm 11.9 \mathrm{nmol} / \mathrm{l}, p<0.001$ ) compared to the girls.

Table 2: Pearson's correlation coefficients between bone parameters with body composition, MET scores, dietary intake and serum 25(OH)D ( $\mathrm{N}=243)$ 


\begin{tabular}{|c|c|c|c|c|}
\hline & TBBMD & TBBMC & LSBMD & LSBMC \\
\hline Weight & $0.736 * *$ & $0.872^{\star \star}$ & $0.596 * *$ & $0.752^{\star \star}$ \\
\hline Height & $0.619 * *$ & $0.862^{\star \star}$ & $0.577^{* *}$ & $0.804^{\star \star}$ \\
\hline LM & $0.745^{\star \star}$ & $0.925^{\star \star}$ & 0.621 ** & $0.827^{\star \star}$ \\
\hline FM & $0.668 * *$ & $0.762^{\star \star}$ & $0.525^{\star \star}$ & $0.635^{\star \star}$ \\
\hline $\mathrm{BF} \%$ & $0.507 * *$ & $0.557^{\star \star *}$ & $0.423^{\star *}$ & $0.452^{\star \star}$ \\
\hline MET scores & $0.278 * \star$ & $0.235^{\star \star}$ & $0.127 *$ & $0.168^{\star \star}$ \\
\hline Energy intake & 0.122 & 0.124 & 0.067 & 0.075 \\
\hline Protein intake & 0.086 & 0.072 & 0.023 & 0.016 \\
\hline Calcium intake & 0.079 & 0.035 & 0.051 & 0.008 \\
\hline Vitamin D intake & -0.009 & -0.055 & -0.004 & -0.056 \\
\hline Serum 25(OH)D & 0.062 & -0.002 & -0.068 & -0.084 \\
\hline
\end{tabular}

Abbreviation: LM, lean mass; FM, Fat mass; BF\%, body fat percentage; $25(\mathrm{OH}) \mathrm{D}, 25$-Hydroxyvitamin $\mathrm{D}$; MET, metabolic equivalent task. Values reported in Pearson's correlation (r). All correlations are significant at ${ }^{*} p<0.01, *_{p}<0.05$.

The association between bone parameters, body composition, MET scores, calcium intake, protein intake and serum 25(OH)D for the total population are shown in Table 2. There were significant correlations between body weight and BMD and BMC at the lumbar spine and total body, as well as with $L M, F M$ and $\mathrm{BF} \%(p<0.005)$. Body weight and MET scores were also significantly correlated $(r=0.147, p<0.05)$. There was a weak, positive correlation between serum 25(OH)D and MET scores $(r=0.256, p<0.01)$, with a negative correlation between serum 25(OH)D and BF\% $(r=-0.159, p<0.05)$. The variables for the stepwise regression analyses included age, height, LM, FM, MET scores, 25(OH)D, protein and calcium intake. Results from stepwise regression analyses for boys and girls are shown in Table 3 and Table 4 respectively.

Table 3 Stepwise regression analysis for predictors of lumbar spine and total body BMD and BMC for boys $(\mathrm{N}=127)$ 


\begin{tabular}{|c|c|c|c|c|c|}
\hline \multirow{2}{*}{$\begin{array}{l}\text { Dependent } \\
\text { variables }\end{array}$} & \multirow{2}{*}{$\begin{array}{l}\text { Significant } \\
\text { predictors }\end{array}$} & \multicolumn{2}{|c|}{ Regression coefficients } & \multirow[t]{2}{*}{$p$-value } & \multirow{2}{*}{$\mathrm{R}^{2}$} \\
\hline & & $\begin{array}{l}\text { Unstandardized } \\
\text { (B) }\end{array}$ & $\begin{array}{l}\text { Standardized } \\
(\beta)\end{array}$ & & \\
\hline \multirow[t]{3}{*}{ LSBMC } & LM & 0.0005 & 0.539 & $<0.001$ & 0.732 \\
\hline & Height & 0.184 & 0.346 & $<0.001$ & \\
\hline & Constant & -13.973 & & $<0.001$ & \\
\hline \multirow[t]{2}{*}{ LSBMD } & LM & 0.00001 & 0.607 & $<0.001$ & 0.364 \\
\hline & Constant & 0.510 & & & \\
\hline \multirow[t]{3}{*}{ TBBMC } & LM & 0.030 & 0.675 & $<0.001$ & 0.866 \\
\hline & Height & 7.564 & 0.282 & $<0.001$ & \\
\hline & Constant & -537.780 & & & \\
\hline \multirow[t]{4}{*}{ TBBMD } & LM & 0.00001 & 0.481 & $<0.001$ & 0.583 \\
\hline & FM & 0.000002 & 0.261 & 0.034 & \\
\hline & MET score & 0.00002 & 0.163 & 0.026 & \\
\hline & Constant & 0.579 & & & \\
\hline
\end{tabular}

Abbreviation: LS, lumbar spine; TB, total body; BMC, bone mineral content; $\mathrm{BMD}$, bone mineral density; LM, lean mass; FM, Fat mass; MET, metabolic equivalent task. The tested variables were age, height, lean mass, fat mass, MET scores, 25(OH)D, calcium and protein intake.

Among the boys, LSBMC was significantly associated with $\operatorname{LM}(\beta=0.539, p<0.001)$ and height $(\beta$ $=0.346, p<0.001)$ with an R-square value of 0.732 . LSBMD was significantly associated with only LM ( $\beta$ $=0.607, p<0.001)$ and the R-square value was 0.364 . TBBMC was significantly associated with LM $(\beta=$ $0.675, p<0.001)$ and height $(\beta=0.282, p<0.001)$. The $\mathrm{R}$-square value was 0.866 . TBBMD was significantly associated with $\operatorname{LM}(\beta=0.481, p<0.001), F M(\beta=0.261, p=0.034)$ and MET Score $(\beta=0.163$, $p=0.026)$ and the R-square value was 0.583 .

Table 4 Stepwise regression analysis for predictors of lumbar spine and total body BMD and BMC for girls $(\mathrm{N}=116)$ 


\begin{tabular}{|c|c|c|c|c|c|}
\hline \multirow{2}{*}{$\begin{array}{l}\text { Dependent } \\
\text { variables }\end{array}$} & \multirow{2}{*}{$\begin{array}{l}\text { Significant } \\
\text { predictors }\end{array}$} & \multicolumn{2}{|c|}{ Regression coefficient } & \multirow[t]{2}{*}{$p$-value } & \multirow[t]{2}{*}{$\mathrm{R}^{2}$} \\
\hline & & $\begin{array}{l}\text { Unstandardized } \\
\text { (B) }\end{array}$ & $\begin{array}{l}\text { Standardized } \\
(\beta)\end{array}$ & & \\
\hline \multirow[t]{4}{*}{ LSBMC } & LM & 0.001 & 0.620 & $<0.001$ & 0.743 \\
\hline & Height & 0.163 & 0.274 & 0.004 & \\
\hline & Calcium & 0.003 & 0.102 & 0.034 & \\
\hline & constant & -15.798 & & 0.008 & \\
\hline \multirow[t]{2}{*}{ LSBMD } & LM & 0.00001 & 0.700 & $<0.001$ & 0.490 \\
\hline & constant & 0.446 & & & \\
\hline \multirow[t]{5}{*}{ TBBMC } & LM & 0.024 & 0.543 & $<0.001$ & 0.895 \\
\hline & Height & 7.897 & 0.340 & $<0.001$ & \\
\hline & FM & 0.005 & 0.123 & 0.036 & \\
\hline & Calcium & 0.139 & 0.122 & $<0.001$ & \\
\hline & constant & -566.616 & & & \\
\hline \multirow[t]{3}{*}{ TBBMD } & LM & 0.00001 & 0.747 & $<0.001$ & 0.573 \\
\hline & Calcium & 0.00001 & 0.197 & 0.002 & \\
\hline & constant & 0.506 & & & \\
\hline
\end{tabular}

Abbreviation: LS, lumbar spine; TB, total body; BMC, bone mineral content; BMD, bone mineral density; LM, lean mass; FM. The tested variables were age, height, lean mass, fat mass, MET scores, 25(OH)D, calcium and protein intake.

Among the girls, LSBMC was significantly associated with $\operatorname{LM}(\beta=0.620, p=<0.001)$ and height $(\beta$ $=0.274, p=0.004)$ and calcium intake $(\beta=0.102, p=0.034)$. The R-square value was 0.743 . LSBMD was significantly associated with only $\operatorname{LM}(\beta=0.700, p<0.001)$ with an $\mathrm{R}$-square value of 0.490 . TBBMC was significantly associated with LM $(\beta=0.543, p<0.001)$, height $(0.340, p<0.001)$, calcium intake $(b=$ $0.123, p<0.001)$ and FM $(\beta=0.122, p=0.036)$. The $\mathrm{R}$-square value was 0.895 . TBBMD was significantly associated with $\operatorname{LM}(\beta=747, p<0.001)$ and calcium intake $(\beta=0.197, p=0.002)$ with the $R$-square value of 0.573 .

The study further investigated the diet and lifestyle factors associated with LM status in the participants. LM was weakly correlated to MET scores $(r=0.205, p=0.001)$ but not protein $(r=0.055, p=0.393)$ or energy intake $(r=0.101, p=0.117)$ (Table 5). 
Table 5: Pearson's correlation coefficients between lean mass, anthropometry, MET scores, protein and energy intakes $(\mathrm{N}=243)$

\begin{tabular}{|lll|}
\hline & Lean Mass & $p$-value \\
\hline MET score & 0.205 & $0.001^{*}$ \\
\hline Weight & 0.945 & $0.001^{*}$ \\
\hline Height & 0.861 & $0.001^{\star}$ \\
\hline Protein intake & 0.055 & 0.393 \\
\hline Energy intake & 0.101 & 0.117 \\
\hline
\end{tabular}

Correlation was tested using Pearson's test. ( $\left.{ }^{*} p<0.05,{ }^{*} p<0.01\right)$.

A step-wise regression analyses showed that the significant predictor of LM was MET scores $(\beta=0.207, p$ $=0.043$ ) in boys but no significant factors were found to predict LM in girls.

Table 6: Stepwise regression analysis for predictors of the lean mass for boys $(\mathrm{N}=127)$

\begin{tabular}{|c|c|c|c|c|c|}
\hline \multirow[t]{3}{*}{ Dependent variables } & \multirow[t]{3}{*}{ Significant predictors } & \multicolumn{2}{|c|}{ Regression coefficients } & \multirow[t]{3}{*}{$p$-value } & \multirow[t]{3}{*}{$\mathrm{R}^{2}$} \\
\hline & & Unstandardized & Standardized & & \\
\hline & & (B) & ( $\beta)$ & & \\
\hline \multirow[t]{2}{*}{ LM } & MET scores & 2.227 & 0.207 & 0.019 & 0.043 \\
\hline & Constant & 20364.6 & & & \\
\hline
\end{tabular}

Abbreviation: LM, lean mass; MET, metabolic equivalent task.

The tested variables were lean mass, MET scores, protein intake and energy intake.

\section{Discussion}

This is the first study in Malaysia and one the few studies in Asian countries reporting the association between modifiable lifestyle factors and body composition on BMD and BMC in pre-adolescent children. Other studies have reported on determinants of Asian adolescent bone health status using bone ultrasound (22-24). 
In this study, $15.2 \%$ of the participants were overweight and another $17.7 \%$ were obese.

These figures are reflective of the nationally reported prevalence of overweight and obesity, $14.4 \%$ and $20.1 \%$ respectively, for children aged 7-12 years old (30). The prevalence of childhood obesity is alarmingly high in Malaysia as compared to other Asian countries as determined by a meta-analysis which reported that the pooled prevalence, overall for boys and girls aged 5-11 years, was only 5.8\% (25). The sex differences observed in our study are also reflective of worldwide trends whereby boys are often reported to have a higher prevalence of obesity than girls (25). Our study reported a higher BF\% in girls as opposed to boys that had a higher LM and TBBMD/BMC. These findings are typically observed in prepubertal children and influenced by hormonal effects and other phenomena (26).

This study also determined that LM was highly correlated with BMC and BMD and that it was the strongest determinant of BMC and BMD of total body and lumbar spine in boys and girls, among other determinants including FM, calcium intake, energy intake, protein intake, serum 25(OH)D and physical activity. Two published studies from India and Iran amongst adolescents (mean age ranged from 13.215.4 years old) reported a positive association between lean mass and bone parameters as measured by DXA $(27,28)$. The magnitude of the correlation between LM with BMC and BMD $(0.8$ and above $)$ in the present study is similar to the studies reported in Caucasian children of a similar age group (29-31). Furthermore, our finding is aligned with the systematic review by Sioen et al. (7) which reported that LM was a stronger determinant of bone parameters as measured by DXA than FM and BF \%. The effect of LM on bone mass has been attributed to the higher tensile force LM exerts on bone as explained by the mechanostat theory (32-35). Recently, it has been reported that the production of insulin-like growth hormone factor-1 (IGF-1) exerts a positive effect on osteogenesis before menarche. Moreover, Interleukin 6 (IL-6) had shown an impact on bone metabolism, however, whether the impact is favourable to bone formation remains unclear (36-38).

Based on the regression analyses, the effect of FM on TBBMD and TBBMC is much less than for LM. Fat mass may exert an equivalent mechanostat function as $\operatorname{LM}(39,40)$ but the stimulation of bone cells by FM is not as effective as LM. Given that almost $33 \%$ of the participants in our study were overweight and obese, it is interesting to observe that LM instead of FM was more beneficial for bone accrual in this population. Farr et al. reported that in young girls aged 8-13 years old, FM is correlated with volumetric $B M D$, periosteal circumference and strength; however, this FM effect was significantly attenuated after adjustment for muscle/lean mass (41). Muscle adiposity was reported to have a negative impact on metabolic function such as insulin resistance, and thus, may negatively influence cortical bone geometry (42). Controlling muscle adiposity (e.g. fat-muscle ratio) in obesity may a provide better understanding on the relationship between body adiposity and bone acquisition in growing children.

The present study confirmed that height is also a significant determinant of BMC in boys and girls at both the total body and lumbar spine. It is well documented that BMC and BMD measurements by DXA are affected by height (43). The participants in our study were experiencing rapid growth and as McCormack et al. reported, as the skeleton grows and expands, BMC also increases exponentially (44). 
Physical activity of the participants in our study as measured by MET scores correlated with LM and bone parameters. Boys were found to be more physically active than girls and their MET score was found to be a significant contributor to TBBMD, but not in girls. Physical activity is known to influence bone health through a similar mechanism as LM whereby activation of the mechanosensitive cells, osteocytes, embedded within the bone, signal molecules to stimulate osteogenesis (5).

We demonstrated that physical activity was the main predictor for LM in boys but not girls. The literature supports that weight-bearing and ground reaction force (GRF) are important for bone growth $(20,45)$. A systematic review highlighted the significant changes in bone structure (cortical thickness and bone area) in response to mechanical loading and muscle function (45). Majority of the boys in our study were involved in moderate to vigorous sports activities with high GRF such as running (MET intensity = 7.7), hockey and handball (MET intensity $=6.0$ ). In contrast, the girls were generally involved in sports activities with shorter duration and lower intensity such as aerobics exercise (MET intensity $=5.0)$ and dancing (MET intensity = 4.0) during physical education classes, although some activities were as great as that for boys, i.e. hockey.

Calcium intake was significantly correlated with TBBMD, TBBMC and LSBMC amongst girls in this study. The participants had an average calcium intake that only met one-third of the national recommended calcium intake of $1300 \mathrm{mg}$ (46) for adequate growth and bone health. Low calcium intakes are correlated with low BMD in Asian children and exert a negative impact on growth and adult height $(47,48)$. More studies are needed to verify this relationship in other Asian populations.

About $40 \%$ of the children in this cohort had inadequate serum $25(\mathrm{OH}) \mathrm{D}$ level $(<40 \mathrm{nmol} / \mathrm{L})(49)$. The girls had a significantly lower serum $25(\mathrm{OH}) \mathrm{D}$ status as compared to boys. This finding can be explained by the fact that majority of the girls in our study have lower exposure to sunlight due to their religious attire, which only leaves their face exposed. Furthermore, the girls also had lower levels of physical activity as compared to boys, reflecting less outdoor activities and exposure to the sun. However, neither our study nor a similar study among preadolescent children in South Africa with low levels of serum vitamin $D$ showed any association between bone parameters and levels of 25(OH)D (31).

The study had predominantly Malay ethnicity among the study participants, a previously understudied group. Future studies should include other ethnic groups to elucidate whether the findings are similar in Chinese and Indian children in Malaysia. A strength of the study was the analysis of serum vitamin D using LC/MS/MS which is considered gold standard and the use of DXA to determine bone parameters, but a limitation was that we were not able to determine volumetric bone mass, microarchitecture of bone, or the fat-bone relationship with respect to visceral, bone marrow, and muscular adiposity. The range of some parameters in this cohort including calcium intake, vitamin D status and bone indices may have been too narrow to determine their full effects on bone, though these parameters were representative of growing pre-adolescent Asian children.

\section{Conclusion}


The results of our study confirm that LM is the major determinant of BMC and BMD at the lumbar spine and total body among pre-adolescent Malaysian children with low calcium intakes and low vitamin $\mathrm{D}$ status. Encouraging physical activity, calcium intake and optimum diets that build lean body mass should be the focus for developing public health guidance to ensure optimal bone health status during rapid growth.

\section{Abbreviations}

PBM : peak bone mass

LS: Lumbar spine

TB: Total body

$\mathrm{BMD}$ :bone mineral density

$\mathrm{BMC}$ : bone mineral content

SCF: soluble corn fibre

25-OHD: serum 25-hydroxyvitamin D

DXA: dual-energy X-ray absorptiometry

MET: total metabolic equivalent

CPAQ: Physical activety questionnaire for children

LC-MS/MS: Liquid chromatography-tandem mass spectrometer

LM: Lean mass

FM: Fat mass

PA: Physical activity

BMI: Body mass index

\section{Declarations}

\section{Author's contribution}

Chang CY : Investigation, Formal analysis, Data curation, Writing - original draft Arasu K: Investigation, Data curation, Writing- review \& editing Wong SY : Investigation, Data curation, Writing - review \& editing Ong SH : Investigation, Writing - review \& editing Yang WY : Investigation, Writing - review \& editing 
Chong MZH : Investigation, Writing - review \& editing Meenal M : Investigation, Writing - review \& editing Khoo EJ : Investigation, Writing - review \& editing Karuthan C : Formal analysis Weaver CM :

Conceptualization, Writing - review \& editing Chee WSS : Conceptualization, Methodology, Investigation, Writing - original draft, Visualization, Supervision, Project administration, Funding acquisition

WSSC and CMW conceived of and designed the study. KA, CYC, SYW, SHO, WYY, MZHC, MM, EJK, WSSC contributed to the acquisition of the data. KA, WSSC and KC analyzed and interpreted the data. KAN and WSSC drafted the manuscript. SHO, WYY, MZHC, MM, EJK, CMW substantively revised it. WSSC acquired the funding for the conduct of the study. All authors have read and approved the final manuscript.

\section{Ethics approval and consent to participate}

The trial obtained ethical approval from the Research and Ethics Committee of the International Medical University (IMU R182/2016) on $21^{\text {st }}$ July 2016 and conforms to the human subject guidelines provisions of the Declaration of Helsinki in 1995 (as revised in Edinburgh 2000). Informed consent was obtained from parents or legal guardians and assents obtained from the participants. Participants anonymity was preserved.

Consent to publish

Not applicable

Availability of data and materials

Not applicable

Competing interest

None declared

\section{Funding}

Funding of this study was provided by Tate \& Lyle Ingredients Americas LLC. The sponsoring body had no role in the study design, implementation, outcome and publication of the study.

\section{Acknowledgement}

The authors thank all the participants, parents, and teachers as well as research assistants/ enumerators in this study

\section{References}

1. Golden NH, Abrams SA, nutrition Co. Optimizing Bone Health in Children and Adolescent. American Academy of Pediatrics. 2014;134(4):e1229-e43. DOI:10.1542/peds.2014-2173. 


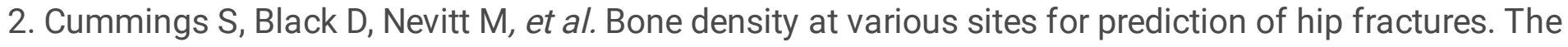
Study of Osteoporotic Fractures Research Group. Lancet. 1993;341(8837):72-5. DOI:10.1016/01406736(93)92555-8.

3. Levine MA. Assessing bone health in children and adolescents. Indian Journal of Endocrinology and Metabolism. 2012;16(Supplement 2):205-12. DOI:10.4103/2230-8210.104040.

4. Bachrach LK. Acquisition of optimal bone mass in childhood and adolescence. Trends in Endocrinology \& Metabolism. 2001;12(1). DOI:10.1016/S1043-2760(00)00336-2.

5. Weaver C, Gordon C, Janz K, et al. The National Osteoporosis Foundation's position statement on peak bone mass development and lifestyle factors: a systematic review and implementation recommendations. Osteoporosis International. 2016;27(4):1281-386. DOI:10.1007/s00198-015-34403.

6. Gunter KB, Almstedt HC, Janz KF. Physical Activity in Childhood May Be the Key to Optimizing Lifespan Skeletal Health. Exercise and Sport Sciences Review. 2012;40(1):13-21.

DOI:10.1097/JES.0b013e318236e5ee.

7. Sioen I, Lust E, Henauw SD, et al. Associations Between Body Composition and Bone Health in Children and Adolescents: A Systematic Review. Calcified Tissue International. 2016;99(6):557-77. DOI:10.1007/s00223-016-0183-x.

8. Cooper C, Cole, Holroyd C, et al. Secular trends in the incidence of hip and other osteoporotic fractures. Osteoporosis International. 2011;22(5):1277-88. DOI:10.1007/s00198-011-1601-6.

9. Ashraf M, Ishaq M, Parrey NA, et al. Vitamin D deficiency in children. Asian Journal of Medical Sciences. 2014;6(1). DOI:10.3126/ajms.v6i1.10199.

10. Poh BK, Ng BK, Haslinda MDS, et al. Nutritional status and dietary intakes of children aged 6 months to 12 years: findings of the Nutrition Survey of Malaysian Children (SEANUTS Malaysia). British Journal of Nutrition. 2013;110:S21-S35. DOI:10.1017/S0007114513002092.

11. Khor GL, Chee WS, Shariff ZM, et al. High prevalence of vitamin D insufficiency and its association with BMI-for-age among primary school children in Kuala Lumpur, Malaysia. BMC Public Health. 2011;11(95). DOI:10.1186/1471-2458-11-95.

12. Wong JE, Parikh P, Poh BK, et al. Physical Activity of Malaysian Primary School Children: Comparison by Sociodemographic Variables and Activity Domains. Asia Pacific Journal of Public Health. 2016;28(5 Suppl):35S-46S. DOI:10.1177/1010539516650726.

13. Sharif R, Chong KH, Zakaria NH, et al. Results From Malaysia's 2016 Report Card on Physical Activity for Children and Adolescents. Journal of Physical Activity and Health. 2016;13(Suppl 2):S201-S5. DOI:10.1123/jpah.2016-0404.

14. Yang WY, Burrows T, MacDonald-Wicks L, et al. Body Weight Status and Dietary Intakes of Urban Malay Primary School Children: Evidence from the Family Diet Study. Children. 2017;4(5). DOI:10.3390/children4010005.

15. International Standards for Anthropometric Assessment Micheal Marfell-Jones ed: International Society for the Advancement of Kinanthropometry (ISAK); 2001. 
16. Onis Md, Onyango AW, Borghi E, et al. Development of a WHO growth reference for school-aged children and adolescents. Bulletin of the World Health Organization. 2007;85(9). DOI:10.2471/BLT.07.043497.

17. Xu H, Chen J-X, Gong J, et al. Normal Reference for Bone Density in Healthy Chinese Children. Journal of Clinical Densitometry. 2007;10(3):266-75. DOI:10.1016/j.jocd.2007.05.005.

18. Aini JN, Poh BK, Chee WSS. Validity of a children's physical activity questionnaire (cPAQ) for the study of bone health. Pediatrics International. 2013;55:223-8. DOI:10.1111/ped.12035.

19. Ainsworth BE, Haskell WL, Whitt MC, et al. Compendium of Physical Activities: an update of activity codes and MET intensities. Medicine and Science in Sports and Exercise. 2000;32(9 suppl):S498S504. DOI:10.1097/00005768-200009001-00009.

20. Kemper H, Bakker I, Twisk JW, et al. Validation of a Physical Activity Questionnaire to Measure the Effect of Mechanical Strain on Bone Mass. Bone. 2002;30(5):799-804. DOI:10.1016/s87563282(02)00709-3.

21. Kim H-Y. Statistical notes for clinical researchers: assessing normal distribution (2) using skewness and kurtosis. Restorative Dentistry \& Endodontics. 2013;38(1):52. DOI:10.5395/rde.2013.38.1.52.

22. Zulfarina MS, Sharif R, Syarifah-Noratiqah S-B, et al. Modifiable factors associated with bone health in Malaysian adolescents utilising calcaneus quantitative ultrasound. PLOS ONE. 2018;13(8). DOI:10.1371/journal.pone.0202321.

23. Suriawati AA, Majid HA, Al-Sadat N, et al. Vitamin D and Calcium Intakes, Physical Activity, and Calcaneus BMC among School-Going 13-Year Old Malaysian Adolescents. Nutrients. 2016;8(666). DOI:10.3390/nu8100666.

24. Srichan W, Thasanasuwan W, Kijboonchoo K, et al. Bone status measured by quantitative ultrasound: a comparison with DXA in Thai children. European Journal of Clinical Nutrition. 2015;70:894-7. DOI:10.1038/ejcn.2015.180.

25. Mazidi M, Banach M, Kengne AP. Prevalence of childhood and adolescent overweight and obesity in Asian countries: a systematic review and meta-analysis. Archives of Medical Science. 2018;14(6):1185-203. DOI:10.5114/aoms.2018.79001.

26. Garnett SP, Högler W, Blades B, et al. Relation between hormones and body composition, including bone, in prepubertal children. American Journal of Clinical Nutrition. 2004;80(4):966-72. DOI:10.1093/AJCN/80.4.966.

27. Marwaha RK, Garg MK, Bhadra K, et al. Bone mineral content has stronger association with lean mass than fat mass among Indian urban adolescents. Indian J Endocrinol Metab. 2015;19(5):60815. DOI:10.4103/2230-8210.163174.

28. Jeddi M, Dabbaghmanesh MH, Ranjbar Omrani G, et al. Relative Importance of Lean and Fat Mass on Bone Mineral Density in Iranian Children and Adolescents. Int J Endocrinol Metab. 2015;13(3):e25542. DOI:10.5812/ijem.25542v2.

29. Gracia-Marco L, Ortega FB, Jiménez-Pavón D, et al. Adiposity and bone health in Spanish adolescents. The HELENA study. Osteoporosis International. 2012;23:937-47. DOI:10.1007/s00198- 
011-1649-3.

30. Baptista Ft, Barrigas C, Vieira F, et al. The role of lean body mass and physical activity in bone health in children. Journal of Bone and Mineral Metabolism. 2012;30:100-8. DOI:10.1007/s00774-011-02944.

31. White Z, White S, Dalvie T, et al. Bone Health, Body Composition, and Vitamin D Status of Black Preadolescent Children in South Africa. Nutrients. 2019;11(1243). DOI:10.3390/nu11061243.

32. Vicente-Rodriguez G, Ara I, Perez-Gomez J, et al. Muscular development and physical activity as major determinants of femoral bone mass acquisition during growth. Br J Sports Med. 2005;39(9):611-6. DOl:10.1136/bjsm.2004.014431.

33. Rauch F, Bailey DA, Baxter-Jones A, et al. The 'muscle-bone unit' during the pubertal growth spurt. Bone. 2004;34(5):771-5. DOI:10.1016/j.bone.2004.01.022.

34. Schoenau E, Frost H. The "Muscle-Bone Unit" in Children and Adolescents. Calcified Tissue International. 2002;70:405-7. DOI:10.1007/s00223-001-0048-8.

35. Courteix D, Lespessailles E, Loiseau-Peres $S$, et al. Lean tissue mass is a better predictor of bone mineral content and density than body weight in prepubertal girls. . Revue du rhumatisme. 1998;65(5):328-6.

36. Brotto M, Bonewald L. Bone and muscle: Interactions beyond mechanical. Bone. 2015;80:109-14. DOI:10.1016/j.bone.2015.02.010.

37. Bakker AD, Jaspers RT. IL-6 and IGF-1 Signaling Within and Between Muscle and Bone: How Important is the mTOR Pathway for Bone Metabolism? Curr Osteoporos Rep. 2015;13(3):131-9. DOI:10.1007/s11914-015-0264-1.

38. Xu L, Wang Q, Wang Q, et al. Concerted actions of insulin-like growth factor 1, testosterone, and estradiol on peripubertal bone growth: a 7-year longitudinal study. J Bone Miner Res. 2011;26(9):2204-11. DOI:10.1002/jbmr.422.

39. Rokoff LB, Rifas-Shiman SL, Switkowski KM, et al. Body composition and bone mineral density in childhood. Bone. 2019;121:9-15. DOI:10.1016/j.bone.2018.12.009.

40. Soininen S, Sidoroff V, Lindi V, et al. Body fat mass, lean body mass and associated biomarkers as determinants of bone mineral density in children 6-8 years of age - The Physical Activity and Nutrition in Children (PANIC) study. Bone. 2018;108:106-14. DOI:10.1016/j.bone.2018.01.003.

41. Farr JN, Chen Z, Lisse JR, et al. Relationship of total body fat mass to weight-bearing bone volumetric density, geometry, and strength in young girls. Bone. 2010;46(4):977-84. DOI:10.1016/j.bone.2009.12.033.

42. Kindler JM, Lewis RD, Hamrick MW. Skeletal muscle and pediatric bone development. Curr Opin Endocrinol Diabetes Obes. 2015;22(6):467-74. DOI:10.1097/MED.0000000000000201.

43. Bachrach LK, Gordon CM. Bone Densitometry in Children and Adolescents. American Academy of Pediatrics. 2016;138(4):e1-e7. DOI:10.1542/peds.2016-2398. 
44. McCormack SE, Cousminer DL, Chesi A, et al. Association Between Linear Growth and Bone Accrual in a Diverse Cohort of Children and Adolescents. JAMA Pediatrics. 2017;171(9):e171769. DOI:10.1001/jamapediatrics.2017.1769.

45. Tan VP, Macdonald HM, Kim S, et al. Influence of Physical Activity on Bone Strength in Children and Adolescents: A Systematic Review and Narrative Synthesis. Journal of Bone and Mineral Research. 2014;29(10):2161-81. DOI:10.1002/jbmr.2254.

46. Chee WSS. Chapter 17: Calcium. RNI: Recommended nutrient intakes for Malaysia. Malaysia: Ministry of Healh Malaysia; 2017. p. 301-39.

47. Fang A, Li K, Li H, et al. Low Habitual Dietary Calcium and Linear Growth from Adolescence to Young Adulthood: results from the China Health and Nutrition Survey. Scientific Reports. 2017;7(9111). DOI:10.1038/s41598-017-08943-6.

48. Burrows M, Baxter-Jones A, Mirwald R, et al. Bone Mineral Accrual Across Growth in a Mixed-Ethnic Group of Children: Are Asian Children Disadvantaged from an Early Age? Calcified Tissue International. 2009;84(5):366-78. DOI:10.1007/s00223-009-9236-8.

49. Institute of Medicine. Dietary reference intakes for calcium and vitamin D. Washington, DC: The National Academies Press, 2011. 